\title{
Maturity Effects On Students' Perceptions Of How Accounting Scandals Impact The Accounting Profession
}

Peter Theuri, Northern Kentucky University

Andrea Weickgenannt, (Email: weickgenannt@nku.edu), Northern Kentucky University

\begin{abstract}
This study examines the impact of recent ethical scandals on business students' perceptions of the accounting profession and related regulatory reforms, and whether such perceptions may be differentiated by maturity. Student maturity is distinguished by age, class standing, and number of accounting classes taken so far. The study results are based on a survey of student perceptions regarding their understanding of recent accounting scandals and related regulations, the adequacy of the response (from the profession as well as Congress) to these scandals, and the ensuing viability of the accounting profession. Student maturity is found to be a significant determinant of differentiation in these perceptions. Among the results presented, it is interesting to note that more mature students perceive the accounting profession as being more viable than less mature students; however, less mature students purport to have a better understanding of the ethical scandals. The findings of this study have important implications for academicians in their efforts to engage students in meaningful dialog regarding ethical and professional issues.
\end{abstract}

\section{INTRODUCTION}

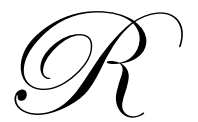

ecent accounting scandals have resulted in a wave of negative publicity for the accounting profession. The bankruptcies of Enron, WorldCom, Sunbeam, and others, and the related accounting improprieties at these companies have led many in the business world (including students and professors) to question the viability of the accounting profession. While those already in the profession may be concerned about mechanisms to control damage and/or strategies to fix the problem, those who are preparing to enter the profession (e.g. students), may be more concerned that the qualities that attracted them to pursue the profession may be eroding.

Despite the negative publicity, there are some positive outcomes of these scandals. In particular, the heightened awareness of ethical issues and the augmented role of accountants have presented opportunities for academicians to discuss relevant topics in their courses. In addition, the regulatory reaction to these scandals has been noteworthy, as the enactment of the Sarbanes-Oxley Act of 2002 and Statements on Auditing Standards (SAS) No. 99 brought sweeping changes to the profession.

This study examines whether students' perceptions of the impact recent ethical scandals and related regulatory actions have had on the accounting profession can be differentiated by student maturity. In essence, this study presents how differences in student maturity are related to students' perceptions about the impact of accounting scandals on the accounting profession. Student maturity is determined by three differentiations: age, class standing (sophomore, junior, etc.), and number of accounting courses taken. Several dimensions of students' perceptions are measured, such as whether students perceive the accounting profession as viable both before and after the occurrence of the scandals that shook the accounting profession in the early 2000s. In addition, students' perceptions are evaluated as to whether the regulatory actions taken are adequate. 
While prior studies have concentrated on the overall value judgment of ethical issues, the findings of this study should contribute to the ethics literature by evaluating students' ethics-based perceptions with maturity as the differentiating variable. The results should be of value in the development of well-structured classroom agenda that fit the student audience with the goal of helping students understand ethics and the regulatory process. It is imperative that those seeking to enter the accounting profession participate in setting standards and support of standards implementation in order to ensure a continually viable profession.

\section{LITERATURE REVIEW}

The attention to ethical issues in the existing literature has been widespread within the past two decades. Moreover, many researchers have focused on age as a factor in the differences in ethical perceptions of students, with assorted findings. For example, Barnett and Brown (1994) found that age had no effect on the ethical perceptions of students. On the other hand, there are many studies that found significant relationships between ethical judgments and age. Undergraduates were found to be more justice-oriented than MBA students, who tended to be more utilitarian in their approach to ethical dilemmas (Borkowski and Ugras, 1992). Silver and Valentine (2000) found that older students perceived greater moral intensity in an ethical sales situation than did their younger counterparts. Even a meta-analysis of research conducted over a period of one decade in the mid-1980s to1990s pointed toward stronger ethical attitudes of older versus younger students (Borkowski and Ugras, 1998).

When maturity is analyzed based on the student's class standing, research again tends to favor a direct relationship between class standing and ethical attitudes. Silver and Valentine (2000) found a connection between increased higher education and ethical sensitivity, as they concluded that graduate students perceive greater moral intensity than undergraduate students. Additional research results indicate that as students progress from beginning business students to the graduate student level, their ethical perceptions tend to change, with a maturity toward society's expectations (Davis and Welton, 1991). On the other hand, Luthar et al (1997) found that senior business students' perceptions were more cynical than their counterparts of lower class standing. For instance, freshmen were much more likely to have an idealistic view of ethics than seniors.

Finally, although many studies have focused on the relationship between ethical-oriented classroom experience and ethical perceptions, the results have been quite varied. Earlier research tends to negate the notion of a correlation between these factors (Davis and Welton, 1991, and Borkowski and Ugras, 1992 and 1998). However, the study by Luthar et al (1997) found that students who had taken ethical courses were more likely to view ethical dilemmas in an idealistic manner, i.e., with a positive association between ethical behavior and favorable business results. The most recent research suggests a correlation between education and positive attitudes toward ethical accounting matters (Titard et al, 2005; Shaftel and Shaftel, 2005).

Although the results are mixed, the literature suggests that differences in student perceptions about ethical issues may be explained by many demographic factors. Existing research has addressed such differentiators as age, gender, and economic background of the respondents, as well as class standing and exposure to ethical teaching. Some authors (Borkowski and Ugras, 1992 and Luthar et al, 1997) concluded that the differences in ethical perceptions may be due to idealism in the undergraduate groups and/or employment experience in the MBAs. This study expands upon the existing literature by focusing on differences in students' perceptions of the effect accounting ethics-related scandals have had on the profession as a function of maturity, with maturity defined by age, class standing, and exposure to accounting coursework.

\section{METHODOLOGY}

A survey questionnaire was developed to elicit perceptions about accounting at a time when there have been a number of significant accounting scandals (stemming from entities such as Enron and WorldCom). The survey was posted on the internet for easy accessibility. Students were sent an email asking them to click on the provided link in order to access the survey. Once completed, students clicked on the "submit" button and the results were sent to the researchers. 120 responses were received with 117 usable responses. Table 1 presents a summary profile of students. Approximately $62 \%$ of the respondents were female. About $65 \%$ of the respondents were accounting majors or intended to pursue accounting as a major while the rest had a major within the college of 
business. Approximately 17\% were under 20 years old, and $48 \%$ were between 21 and 24, and 35\% were over 24 years old. About $33 \%$ were juniors, $37 \%$ seniors, and $17 \%$ were sophomores.

Table 1

Summary Profile of Respondents $\mathbf{N}=117$

\begin{tabular}{|c|c|c|c|}
\hline \multicolumn{4}{|c|}{$\mathrm{N}=117$} \\
\hline & & Frequency & Percent \\
\hline \multirow[t]{2}{*}{ Gender: } & Female & 72 & $62 \%$ \\
\hline & Male & 45 & $38 \%$ \\
\hline \multirow[t]{4}{*}{ Age: } & Under 20 & 20 & $17 \%$ \\
\hline & $21-24$ & 56 & $48 \%$ \\
\hline & $25-28$ & 7 & $6 \%$ \\
\hline & Over 28 & 34 & $29 \%$ \\
\hline \multirow{2}{*}{ Major: } & Accounting & 76 & $66 \%$ \\
\hline & Others (all in Business) & 41 & $34 \%$ \\
\hline \multirow[t]{4}{*}{ Classification: } & Sophomores & 20 & $17 \%$ \\
\hline & Juniors & 38 & $32 \%$ \\
\hline & Seniors & 44 & $38 \%$ \\
\hline & Post-Bach \& Graduate & 15 & $13 \%$ \\
\hline \multirow[t]{4}{*}{ GPA: } & Under 2.49 & 7 & $6 \%$ \\
\hline & $2.59-2.99$ & 24 & $21 \%$ \\
\hline & $3.00-3.49$ & 37 & $32 \%$ \\
\hline & $3.50-4.00$ & 47 & $41 \%$ \\
\hline \multirow[t]{4}{*}{ Accounting Courses Taken: } & Two or less & 53 & $45 \%$ \\
\hline & Between three and four & 15 & $13 \%$ \\
\hline & Between five and six & 44 & $38 \%$ \\
\hline & No response & 5 & $4 \%$ \\
\hline
\end{tabular}

Table 2 presents a summary of student responses to the survey questions.

Table 2

Summary of Overall Student Perceptions of Effects of Scandals on the Accounting Profession $\mathbf{N}=\mathbf{1 1 7}$

Mean Median

SD

To what extent do you believe

1. the profession remains viable after scandals

\begin{tabular}{l}
5.68 \\
3.62 \\
4.29 \\
3.76 \\
5.54 \\
5.57 \\
4.40 \\
3.87 \\
\hline
\end{tabular}

$6 \quad 1.33$

2. the profession has lost credibility

$3 \quad 1.56$

3. the profession has implemented adequate measures to avoid future scandals

$4 \quad 1.36$

4. that Congress has taken sufficient steps to avoid such future scandals

3

5. the profession can regain future public confidence

$7 \quad 1.31$

6. the profession had prior public confidence

6

7. you understand what was entailed in the scandals

5

8. you understand the recent regulatory reforms

$5 \quad 1.59$

Items in italicized bold are used as variables in Table 3. 
We address two main research questions regarding students' maturity and their perceptual judgments of the impact ethical scandals had on the accounting profession as follows:

- $\quad$ Do student perceptions about various effects on the profession differ based on maturity?

- Do student perceptions about various effects on the profession differ within each maturity measures?

In this study, maturity is represented by age, class standing, and number of courses taken so far.

\section{Preliminary Tests}

A test for a linear relationship between each perception variable and the overall maturity of the subjects was initially performed prior to an investigation of how each of the three measures of maturity (age, number of courses taken, and class standing) impacts the various perception variables of interest. Since the maturity variables are based on categorical data, the Spearman Rho correlation coefficient is used to test for the relationship.

A strong positive linear correlation exists between respondents' age and three perception variables of interests. The number of courses taken by the student also exhibits a strong positive linear correlation with two variables of interest. Class standing has a strong positive correlation with two variables and a modest positive linear relationship with one variable of interest. Table three shows the details of the results. Note that only those variables exhibiting a statistically significant linear relationship are reported.

Table 3

Results of Correlation Coefficients between Students' Perception of Scandals' Effect and Various Maturity Measures

\begin{tabular}{|c|c|c|c|}
\hline & Age & Class & Courses \\
\hline To what extent do you believe... & $r$-coeff.(sign) & $r$-coeff.(sign) & $r$-coeff.(sign) \\
\hline 1. the profession remains viable after scandals & $.258(.005)$ & $.157(.092)$ & None \\
\hline 2. the profession has lost credibility & None & None & None \\
\hline $\begin{array}{l}\text { 3. the profession has implemented adequate } \\
\text { measures to avoid future scandals }\end{array}$ & None & None & None \\
\hline $\begin{array}{l}\text { 4. that Congress has taken sufficient steps } \\
\text { to avoid such future scandals? }\end{array}$ & None & $.194(.038)$ & $.263(.006)$ \\
\hline 5. the profession can regain future public confidence & $.225(.017)$ & None & None \\
\hline 6. the profession had prior public confidence & None & None & None \\
\hline 7. you understood what was entailed in the scandals? & $.208(.027)$ & None & None \\
\hline 8. you understood the recent regulatory reforms & None & $.235(.014)$ & $.193(.049)$ \\
\hline
\end{tabular}

In order to understand the extent to which the reported maturity variables in Table 3 are a factor in influencing the responses to the various perception effects, a least squares regression (reduced and full models) is run with each of the maturity levels as independent variables and each of the perception effects is the dependent variable. Table 4 reports the summary results. 
Table 4

Full and Reduced Regression Models of Overall Impact of Each Maturity Measure on Students' Perception of Scandals' Effect $^{0}$

\begin{tabular}{|c|c|c|c|c|}
\hline (a) & Model & Age & Class & Courses \\
\hline & F-value(sign) & t-value (sign) & t-value (sign) & t-value(sign) \\
\hline \multicolumn{5}{|c|}{ To what extent do you believe the profession remains viable after scandals? } \\
\hline Model with Age only & $8.974(.003)^{* *}$ & $2.996(.003)^{* *}$ & -------- & -------- \\
\hline Model with Class only & $3.942(.049)^{* *}$ & ------- - & $1.986(.049)^{* *}$ & -------- \\
\hline Model with Age \& Class & $4.674(.011)^{* *}$ & $2.154(.033)^{* *}$ & $1.033(.304)$ & -------- \\
\hline Model with Age, Class \& Courses & $4.451(.005)^{* *}$ & $2.519(.013)^{* *}$ & $0.518(.605)$ & $1.189(.237)$ \\
\hline \multirow[t]{2}{*}{ (b) } & Model & Class & Courses & Age \\
\hline & F-value(sign) & $t$-value (sign) & t-value (sign) & t-value (sign) \\
\hline \multicolumn{5}{|c|}{ To what extent do you believe you understood the recent regulatory reforms? } \\
\hline Model with Class only & $4.501(.036)^{* *}$ & $2.121(.036)^{* *}$ & -------- & -------- \\
\hline Model with Class \& Courses & $2.729(.070)^{*}$ & $1.088(.279)$ & $1.381(.170)$ & -------- \\
\hline Model with Class, Courses \& Age & $2.353(.077)^{*}$ & $0.096(.923)$ & $2.487(.015)^{* *}$ & $(.011)(.991)$ \\
\hline \multirow[t]{2}{*}{ (c) } & Model & Class & Courses & Age \\
\hline & F-value(sign) & t-value (sign) & t-value (sign) & t-value (sign) \\
\hline \multicolumn{5}{|c|}{ To what extent do you believe that Congress has taken sufficient steps to avoid such future scandals? } \\
\hline Model with Courses only & $7.187(.008)^{* *}$ & -------- & $2.681(.008)^{* *}$ & -------- \\
\hline Model with Class \& Courses & $3.363(.038)^{* *}$ & $0.261(.795)$ & $2.163(.033)^{* *}$ & -------- \\
\hline Model with Class, Age \& Courses & $2.185(.094)^{*}$ & $0.374(.709)$ & $2.290(.024)^{* *}$ & $(.430)(.668)$ \\
\hline \multicolumn{5}{|c|}{$\begin{array}{l}{ }^{0} \text { Results presented are only for perception effects significantly correlated with two or more maturity variables. See Table } 3 \mathrm{f} \\
\text { correlations results. }\end{array}$} \\
\hline
\end{tabular}

Age is statistically related to students' perception that the profession remains viable after the scandals even after controlling for class standing and number of courses taken [see Table 4(a)]. When age is removed from the model and class standing is introduced by itself, class standing is statistically significant ( $p=.049)$ in explaining student perceptions. In a full model that includes age, class standing, and number of courses taken, neither class standing nor number of courses taken is significant. However, age maintains a statistically significant explanatory power $(p=0.13)$.

In the model that investigates whether students understood the recent regulatory reforms [Table 4(b)], class standing is statistically significant ( $p=.036)$. When number of courses taken is introduced in the model, neither class standing nor number of courses taken is significant. The full model with all three maturity variables shows the number of courses to be statistically significant $(p=.015)$ and no other maturity variables are significant. The significance of the overall full model is much weaker $(p=.077)$ than the model with class standing alone $(p=.036)$.

In the model related to whether Congress has taken sufficient steps to avoid such future scandals [Table 4(c)], the number of courses taken was consistently the only significant maturity variable. It is interesting to note also that the model was weaker as more maturity variables were added in the model.

The regression models reveal that students' perceptions of the effects scandals have on the profession may be differentiated by age while the students' perceptions of the adequacy of reformatory actions may be explained by their class standing and also by the number of courses taken to date. A multiple comparison analysis for each 
maturity variable is warranted in order to make more conclusive statements about how each group within the maturity variables may explain differences in student perceptions.

\section{Multiple Comparison Tests}

Table 5

Results of Multiple Comparison Tests of Students' Perception of Scandals' Effect

\begin{tabular}{|c|c|c|c|}
\hline & Age & Class & Courses \\
\hline & F-value(Sign) & F-value (Sign) & F-value (Sign) \\
\hline \multicolumn{4}{|l|}{ To what extent do you believe .......... } \\
\hline 1. the profession remains viable after scandals & $3.31(.023)$ & $1.96(.125)$ & $1.29(.279)$ \\
\hline 2. the profession has lost credibility & $1.16(.330)$ & $.12(.948)$ & $1.04(.356)$ \\
\hline $\begin{array}{l}\text { 3. the profession has implemented } \\
\text { adequate measures to avoid future scandals }\end{array}$ & $2.42(.070)$ & $1.90(.134)$ & $4.03(.020)$ \\
\hline $\begin{array}{l}\text { 4. that Congress has taken sufficient } \\
\text { steps to avoid such future scandals }\end{array}$ & $.64(.591)$ & $3.11(.030)$ & $6.62(.002)$ \\
\hline 5. the profession can regain future public confidence & $2.36(.075)$ & $.86(.466)$ & $.66(.520)$ \\
\hline 6. the profession had prior public confidence & $.85(.470)$ & $1.07(.363)$ & $.37(.694)$ \\
\hline 7. you understand what was entailed in the scandals & --- & $.86(.466)$ & $.01(.992)$ \\
\hline 8. you understand the recent regulatory reforms & --- & $4.03(.009)$ & $2.19(.118)$ \\
\hline
\end{tabular}

\section{Perceptions Differentiated By Age}

Student respondents were divided into four groups based on age categories of $<20(n=20), 21-24(n=56)$, 25-28 $(\mathrm{n}=6)$, and $>28 \quad(\mathrm{n}=34)$. Older college students, compared with their younger counterparts, perceived significantly more positively that the accounting profession remains a viable profession after the scandals $p=.018$. The statistically significant difference was observed between the $17-20$ and the $>28$ age groups. A moderately significant difference between the same groups was observed when asked the extent to which they believed the accounting profession could regain public confidence in the future $(p=.087)$. When asked to what extent they believed the accounting profession has implemented adequate measures to avoid such future scandals, the 17-20 age group differed significantly $(p=.037)$ from the 21-24 age group. These results are consistent with Silver and Valentine (2000) who find that older students were much more likely to perceive greater moral intensity than younger students. Borkowski and Ugras (1998) found similar results in that older students had stronger ethical attitudes than did the younger students.

\section{Perceptions Differentiated By Class Standing}

Students were divided into four groups based on their classifications of sophomores $(n=20)$, juniors $(n=38)$, seniors $(n=43)$, and advanced students $[(\mathrm{n}=15)$ post-baccalaureate and graduate students]. Sophomores perceived the profession as less viable after the scandals than did the advanced and juniors ( $p=.027$ and $p=.036$, respectively). Juniors, on the other hand, perceived significantly more strongly than did the seniors $(p=.004)$ that Congress has taken sufficient steps to avoid such future scandals. Also, the sophomores and juniors respectively, perceived significantly more strongly than the seniors $(p=.012$ and $p=.002$, respectively) that they understood the recent 
regulatory and ethical reforms put in place. When asked if any of their professors had discussed any of the accounting scandals in class, sophomores, significantly more than seniors and advanced students $(p=.00, p=.05$ respectively), had exposure to such in-class discussions. As a follow-up, when asked whether the discussion was conducted by an accounting professor, again sophomores and juniors, significantly more than seniors ( $p=.00$ and $p=.00$ respectively) answered in the affirmative.

\section{Perceptions Differentiated By Number Of Accounting Course Taken}

Students were grouped into three categories depending on how many accounting courses they had taken as follows: early group $\leq 2(n=53)$; middle group 3-4 $(n=15)$; advanced group $\geq 5(n=44)$. The middle group (3-4 courses) perceived significantly more strongly than did the advanced group that the accounting profession and Congress have implemented adequate measures to avoid similar future scandals ( $p=.007$ and $p=.002$, respectively). Also the early group significantly differed from the advanced group $(p=.006)$ on the same measure, with the advanced group agreeing more positively. The advanced group rated their level of understanding of the recent reforms significantly more strongly than did the early group $(p=041)$. No other significant differences were identified when the number of courses taken was the only differentiating factor.

\section{SUMMARY AND DISCUSSION}

Overall, several interesting findings emerge regarding students' perceptions of the impact recent accounting ethical scandals had on the profession as differentiated by maturity measures. It is clear that the more mature students, when categorized by age, perceived the accounting profession as remaining viable. Titard, et al. (p. 64, 2004) found that "... more informed students appear to view the profession more favorably..." Perhaps life experiences account for such perceptions. If maturity can be captured by the number of accounting courses taken, similar conclusions are evident. The results of this study are consistent with those of previous researchers, especially those that investigate ethical decision-making. It is rather interesting that sophomores and juniors perceived significantly more strongly than did seniors that they understand the nature of recent accounting scandals. This result is well explained by the results showing that sophomores and juniors had more in-class discussions about the scandals than did the seniors. As Titard et al (p. 62, 2004) note, institutions most often left decisions about how to incorporate coverage of the scandals to individual instructors. Introductory accounting courses (taken by sophomores) at the participating university are coordinated by one professor and thus offers more structure into what is covered in the course, including the ethics writing assignment(s).

The findings of this study contribute to the ethics literature by identifying the effect that ethical scandals have on business students' perception of the profession when differentiated by maturity measures. Understanding of this relationship may assist academicians to be more sensitive to their students' needs during periods of such scandals. This is especially important, given the high level of influence teachers have on shaping their students' perceptions and strengthening their ethical position. As Titard et al. (2004) mention, such scandals present an excellent opportunity for faculty to engage students in professional dialog that can be very educational to them. Such dialog can be accomplished by faculty or practicing professionals, who may be invited into classrooms or even in seminar/workshop types of settings. Being able to gauge the quantity and quality of such dialogs is very critical if the discussant is to have an appreciable impact on the listeners. The results of this study point to differences in student perceptions when maturity is the distinguishing element.

Future research may focus on analyzing the effect such students' perceptions of the accounting scandals may have on students' choice of major or career. Another future research possibility is to assess faculty reactions to the accounting scandals and how that influences their teaching. Studies such as these would enhance the overall quality of accounting education especially in periods when the profession is heavily challenged by improper acts of a few. In addition, dialog about these events can help current professionals to promulgate measures of import that can help shape the perceptions of those within and outside the accounting profession. 


\section{REFERENCES}

1. Barnett, T. and G. Brown: 1994, The Ethical Judgments of College Students Regarding Business Issues, Journal of Education for Business 69 (6), 333-337.

2. Borkowski, S.C. and Y.J. Ugras: 1998, Business Students and Ethics: A Meta-Analysis Journal of Business Ethics 17, 1117-1127.

3. Borkowski, S.C. and Y.J. Ugras: 1992, The Ethical Attitudes of Students as a Function of Age, Sex, and Experience Journal of Business Ethics 11, 961-979.

4. Davis, J.R. and R.E. Welton: 1991, Professional Ethics: Business Students' Perceptions, Journal of Business Ethics 10, 451-463.

5. Luthar, H.K., R.A DiBattista and T. Gautschi: 1997, Perception of What the Ethical Climate is and What it Should be: The Role of Gender, Academic Status, and Ethical Education, Journal of Business Ethics 16, 205-217.

6. Shaftel, J. and T.L. Shaftel: 2005, The Influence of Effective Teaching in Accounting on Student Attitudes, Behavior, and Performance, Issues in Accounting Education 20 (3), 231-246.

7. Silver, L.S. and S.R. Valentine: 2000, College Students' Perceptions of Moral Intensity in Sales Situations, Journal of Education for Business 75 (6), 309-314.

8. Titard, P.L., R.L. Braun and M.J. Meyer: 2005, Accounting Education: Response to Corporate Scandals, Journal of Accountancy 198 (5), 59-65.

\section{NOTES}

